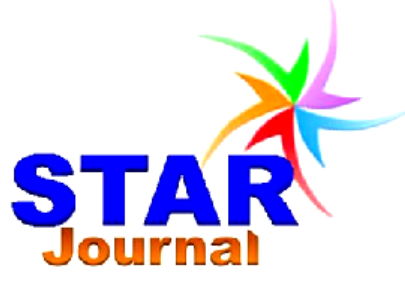

ISSN: 2226-7522(Print) and 2305-3327 (Online) Science, Technology and Arts Research Journal

July-Sep 2013, 2(3): 85-92

www.starjournal.org

Copyright@2013 STAR Journal. All Rights Reserved

Original Research

\title{
Prevalence of Smear Positive Pulmonary Tuberculosis and its Associated Risk Factors among Patients Attending Nekemte Referral Hospital, Western Ethiopia
}

\author{
Eyasu Ejeta*, Adil Ibrahim, AmsaluTefera, Abdulkerim Mohammed and Abdurrahman Said \\ Department of Medical Laboratory Sciences, College of Medical and Health Sciences, Wollega University, \\ Post Box No: 395, Nekemte, Ethiopia
}

\begin{tabular}{|c|c|}
\hline Abstract & Article Information \\
\hline $\begin{array}{l}\text { Tuberculosis (TB), one of the widest spread infectious diseases, is the leading cause of } \\
\text { death in the world. TB is one of the major causes of morbidity and mortality in the horn of } \\
\text { Africa with Ethiopia carrying a heavy burden; it is the third most populous country in } \\
\text { Africa. The aim of this study is to determine the prevalence of smear positive pulmonary } \\
\text { TB (PTB) and its associated risk factors among TB suspected patients attending } \\
\text { Nekemte Referral Hospital. Oromia Region State, Western, Ethiopia. A cross sectional } \\
\text { study was conducted among } 170 \text { TB suspected patients attending Nekemte Referral } \\
\text { Hospital from April } 1 \text { to May } 15,2012 \text {. Convenience sampling technique was used to } \\
\text { select the study subjects. The sputum sample was collected and examined following } \\
\text { national guide line for diagnosis of TB using direct Ziehl - Nelson staining and sodium } \\
\text { hypochlorite concentration techniques. To collect data related to associated risk factors } \\
\text { for PTB, pretest structured question was employed. The collected data was analyzed } \\
\text { using SPSS version } 16 \text { and described using descriptive statistic and binary logistic } \\
\text { regression modeling. The prevalence of smear-positive PTB is } 9.41 \% \text { and } 15.88 \% \text { by } \\
\text { direct and sodium hypochlorite concentration Ziehle-Nelson staining technique, } \\
\text { respectively. Factors significantly associated with smear-positive PTB were level of } \\
\text { education primary (AOR=17.78) and secondary education (AOR=736.19), occupation of } \\
\text { merchant (AOR =0.03), sex male (AOR=0.089), marital status of married (AOR=0.26), } \\
\text { monthly income between } 500-1000 \text { (OR } 0.002) \text {, urban residence (AOR=0.39) and having } \\
\text { close contact history with TB patient (OR=AO.113). The prevalence of Smear positive } \\
\text { PTB is high at the study area and it is mostly associated with soci-demographic factors } \\
\text { and close contact with TB patient. }\end{array}$ & 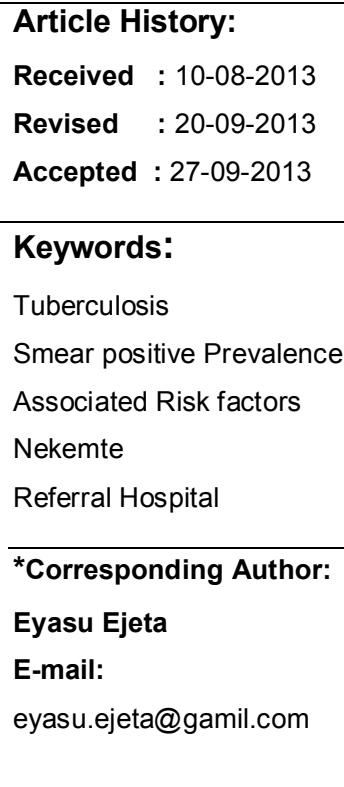 \\
\hline
\end{tabular}

\section{INTRODUCTION}

Tuberculosis (TB), one of the most wide spread infectious disease, is the leading cause of death in the world, while TB control strategy Directly Observed Treatment Short-course (DOTS) is one of the most cost effective interventions (WHO, 2010). More than $81 \%$ of TB cases and deaths comes from developing countries; the TB situation in those countries is aggravated by high prevalence of human immunodeficiency virus, drug resistance, social inequalities, poor TB control efforts and inadequate health care spending (WHO, 2009 and Dye and Williams, 2010).
African countries south of the Sahara including Ethiopia are heavily affected by TB. The World Health Organization (WHO) global reports on TB showed that Ethiopia is among the ten top high burden countries in terms of prevalence or incidence cases of TB (WHO, 2009, and WHO, 2010). According to the $\mathrm{FMOH}$ hospital statistics data, PTB was the third leading cause of hospital admission $(7.8 \%)$, and the first leading cause of inpatient deaths $(10.1 \%)$, and in $2008 / 09$, a total of $145,602(97.8 \%)$ new all forms of TB cases were notified out of which $44,396(30 \%)$ were pulmonary smear positive cases. The case detection rate for smear positive TB cases was very low (34\%) 


\section{Eyasu Ejeta et al.,}

compared to the global target of at least $70 \%$ (FMOH, 2008 and FMOH, 2009). However, the real burden of TB in Ethiopia is not known due to several reasons. First, there is a neither reliable disease notification system nor has any regular nation-wide epidemiological survey of TB and HIV been conducted. Second, Ethiopia has poorly developed diagnostic facilities, developed health information system and low health service coverage which might contribute for the very low case detection rate (FMOH, 2007).

The prevalence of tuberculosis is a useful epidemiological index for measuring the magnitude of the TB problem. It provides useful information for planning a rational control programme and for monitoring progress. However, in developing countries such information is lacking; the reporting system is poorly developed, diagnostic criteria are usually non-standardised and many cases go undetected (Styblo, 1991 and Sudreand Kochi, 1992). Ethiopia is no exception; notification of pulmonary tuberculosis is poor, the diagnostic criteria vary and nation-wide incidence rates are not available (Demissieet al., 2002).

In the absence of a strong surveillance system, institutional-based studies are good alternatives to estimate the burden of TB and to evaluate the impact of the TB control programme. However, to the best of our knowledge there is there is no reliable information on the prevalence of smear positive PTB and its associated risk factors in our study area. Therefore, this study was designed to determine the prevalence of smear positive PTB and its associated risk factors among patients attending Nekemte Referral Hospital, Western Ethiopia.

\section{MATERIALS AND METHODS}

\section{Study Design and Setting}

The Institutional based cross sectional study was conducted from $1^{\text {st }}$ April to $30^{\text {th }}$ May, 2012 at Nekemte Referral Hospital. The Nekemte Referral Hospital was constructed in 1932 by Sweden Missionary and intended to serve 2.1 million peoples annually. The hospital services as referral center for the patients referred to the center from other hospitals, medical centers and private practitioners of East Wollega, West Wollega, Shambu and Keleme Wollega Zones. The hospital is located at Nekemte Town, Western Ethiopia which is $331 \mathrm{~km}$ distant from the capital city of Ethiopia, Addis Ababa. The town has 12 kebeles with total population of over 94,000 and area of $58,400.000 \mathrm{sq} \mathrm{km}$.
Sci. Technol. Arts Res. J., July-Sep 2013, 2(3): 85-92

\section{Study Subjects and Sampling Technique}

A convenient sampling technique was used to select the study subject. All TB suspected patients who requested for PTB sputum examination from in and out patient department of the hospital during the study period, who fulfill the following inclusion criteria of study subject were selected: patients with typical clinical sign and symptom of TB, who did not have history of starting anti TB, able to expectorate sputum, above age of five years and willing to participate in the study. During the study period, 170 study participants who fulfilled the inclusion criteria were obtained.

\section{Data Collection}

The data was collected via face-to-face interviews, in which the translated structured questioner to local language Afan Ormo was used to guide the researcher. All interviews were carried out by three of the investigators to standardize interviews and reduce interview biases.

The structured questionnaire was used in the study was organized in to two sections. The first part was aimed at collecting socio demographic information example, sex, age, religion, academic level, monthly income, ethnicity, occupation, family size, mortal status, residence (rural town) that are served to affect respondents knowledge, attitude and practice on TB prevention. The second and final part was be concerned with the association factors of PTB example smoking, drunk alcohol, drunk raw milk etc.

Before conducting the actual study, the questionnaire was pilot tested at nearby Nekemte Health Center for 10 patients with sign and symptom tuberculosis. The pilot test was used to revise questionnaire clarity, order of questionnaire, skip pattern and for its consistency. Based on the pre-tested feedback, some questions were referred, amended and the final questionnaire was used in the study.

The study participants were visited twice to the Nekemte Referral Hospital Laboratory Sample Collection Unite to provide sample on two consecutive days. Three sputum samples were collected in the early morning from each persontwo spot. They were asked, under supervision, to cough forcibly several times from their lung and expectorate whatever sputum they could produce at the first visit (first spot sample). They were then given a sputum container and asked to repeat the procedure on waking up the next morning (early morning sample). The second spot sample was produced when the early morning sample was brought to the sample collection unite. 


\section{Eyasu Ejeta et al.,}

The collected samples were transported to the Tuberculosis Laboratory Examination Unite of the Hospital. The sputum was then examined for the presence of acid-fast bacilli (AFB) using the standard Ziehl-Neelsen method. All positive and negative samples were checked by a laboratory technician trained by the National Tuberculosis Programme. All individuals found to be positive were contacted by health workers from the Hospital and were put on treatment. TB treatment and followup are provided free of charge at the Hospital.

\section{Data Analysis}

Data were coded, entered and analyzed using SPSS version 16. Descriptive statistics were computed to analyze the socio demogray of the study participants. The logistic regression model was subsequently conducted to identify the independent effect of potential associated risk factors on the outcome of interest (Adjusted OR, Adjusted HR). P-Value less than 0.05 were taken as statistically significant.

\section{Ethical Consideration}

Ethical clearance and permission was obtained from Institutional Review Board (IRB) of College of Medical and Health Sciences, Wollega University. Each participant (patient) was notified about the purpose of the study, the right to refuse for participation in the study, and anonymity and confidentiality of the information. Patients were assured that they will not be penalized for not participating and that their responses to the questions would have no effect on their care.

\section{RESULTS}

\section{Socio Demographic Characteristics of the Study Participants}

A total of 170 clinically suspected tuberculosis (TB) patients were selected to participant in study. The age range of the study participants was from 10 to 80 years. The mean and median age of the study participants were 38 and 36.5 respectively.

Among the total study participants, ninety two $(54.1 \%)$ of them were found in the range of $10-38$ years of age and eighty nine $(52.4 \%)$ of them were male. One hundred five $(61.8 \%)$ of respondents were married. The majority or one hundred sixty $(94.1 \%)$ were Oromo ethnic group. By Religion, eighty seven $(51.2 \%)$ were protestant. Eighty three $(48.8 \%)$ respondents were illiterate. By occupation, eighty one $(47.7 \%)$ of them were farmers. One hundred twenty four $(72.9 \%)$ were from rural. By income, eighty eight $(51.8 \%)$ had monthly income of 100-500 Ethiopian Birr. By family size, ninety two $(54.1 \%)$ of the study participants had $1-5$ family size. One hundred fifty one $(88.8 \%)$ were not
Sci. Technol. Arts Res. J., July-Sep 2013, 2(3): 85-92

currently employed and one hundred thirty five $(79.4 \%)$ of them had mud house (Table 1$)$. Out of 170 respondents, $16(9.41 \%)$ and $27(15.88 \%)$ were positive for AFB by direct and sodium hypochlorite concentration Zeilhe-Neelsen staining technique, respectively.

\section{Smear Positive PTB Associated Risk Factors at the Study Area}

Table 2 shows the assessment of the socio demographic associated factors for TB. In the bivariable analysis, there are no socio demographics associated risk factors. In the multi variable analysis revealed that education level of the primary and secondary; being male; being married and having monthly income of 500-1000 ETB were significantly more likely to have TB while the patient's residing at urban had significantly lower risk.

Table 3 shows the assessment of host related associate factor for TB. In the bi-variable analysis there is no host related associated risk factors were found. In the multi-variable analysis, presence of contact history of TB patient likely to have TB infection more than $86.7 \%$ times.

Table 4 shows the result of multi-variable model assessing for combined socio democratic and host related associated risk factors show that being in the secondary school, previous history contact of TB patient, the resident of urban, sex group of male, occupation of merchant and having monthly income 500-1000 ETB were significantly more likely to have TB. From identified risk factors, having monthly income 500-1000 ETB was found to be lower. However, Primary school and married group are lost significance to be associated risk factor.

\section{DISCUSSION}

The result of our study confirm that the prevalence of smear positive PTB by direct ziehlneeson techniques $9.41 \%$ which is similar to the study conducted in Seka Health Center, Addis Ababa and Nekemte and its surrounding (Demissieet al., 2002, Gebrie and Mimano, 2010, and Eyasu et al., 2012). However, the prevalence obtained by sodium hypochlorite concentration technique was $15.88 \%$ due to the sodium hypochlorite concentration technique increase sensitivity of AFB diagnosis.

In this study, education level (primary and secondary school level), sex (male), marital status (married), monthly income of between 500-1000 ETB and patients who are residing at urban are identified as key risk factors for PTB from sociodemography which is similar to studies conducted in different countries (Philip et al., 2006, TAOI, 1981, 
Table 1: Socio-demography characteristics of (study participants) PTB patients attending Nekemte Referral Hospital, Western Ethiopia, April-May, 2012.

\begin{tabular}{|c|c|c|}
\hline \multicolumn{2}{|c|}{ Characteristics } & Frequency (\%) \\
\hline \multirow[t]{2}{*}{ Age (Year) } & $10-38$ & $92(54.1)$ \\
\hline & $>38$ (Mean) & $78(45.9)$ \\
\hline \multirow[t]{2}{*}{ Sex } & Male & $89(52.4)$ \\
\hline & Female & $81(47.6)$ \\
\hline \multirow[t]{4}{*}{ Marital Status } & Married & $105(61.8)$ \\
\hline & Single & $(18.8)$ \\
\hline & Divorced & $15(8.8)$ \\
\hline & Widowed & $18(10.6)$ \\
\hline \multirow[t]{4}{*}{ Ethnicity } & Oromo & 160(94.1) \\
\hline & Amhara & $7(4.1)$ \\
\hline & Tigre & $1(0.6)$ \\
\hline & Other & $2(1.2)$ \\
\hline \multirow[t]{4}{*}{ Religion } & Protestant & $87(51.2)$ \\
\hline & Muslim & $24(14.2)$ \\
\hline & Orthodox & $56(32.9)$ \\
\hline & Other & $3(1.76)$ \\
\hline \multirow[t]{6}{*}{ Educational level } & Illiterate & $83(48.8)$ \\
\hline & Only read & $1(0.6)$ \\
\hline & Read \& write & $21(12.1)$ \\
\hline & Primary (1-8) & 19(11.2) \\
\hline & Secondary (9-12) & $30(17.6)$ \\
\hline & Higher education $(>12)$ & $16(9.4)$ \\
\hline \multirow{2}{*}{$\begin{array}{l}\text { Do you currently have paid } \\
\text { employment? }\end{array}$} & Yes & $19(11.2)$ \\
\hline & No & $151(88.8)$ \\
\hline \multirow[t]{5}{*}{ Occupation } & Farmer & $81(47.7)$ \\
\hline & Student & $22(12.9)$ \\
\hline & Merchant & $12(7.1)$ \\
\hline & Daily labor & $14(8.2)$ \\
\hline & Other & $41(24.1)$ \\
\hline \multirow[t]{2}{*}{ Total family members } & $1-5$ & $92(54.1)$ \\
\hline & $>5$ (Mean) & $78(45.9)$ \\
\hline \multirow{4}{*}{$\begin{array}{l}\text { Total monthly income of the family } \\
\text { (in Ethiopian birr) }^{*}\end{array}$} & $0-99$ & $25(14.7)$ \\
\hline & $100-499$ & $88(51.8)$ \\
\hline & $500-1000$ & $31(18.2)$ \\
\hline & $>1000$ & $26(15.3)$ \\
\hline \multirow[t]{2}{*}{ Residence area } & Urban & $46(27.1)$ \\
\hline & Rural & $124(72.9)$ \\
\hline \multirow[t]{3}{*}{ Condition of house } & Muddy & $135(79.4)$ \\
\hline & Cemented & $33(19.4)$ \\
\hline & Mixed & $2(1.2)$ \\
\hline \multicolumn{2}{|c|}{ Total } & $170(100 \%)$ \\
\hline
\end{tabular}


Table 2: Socio-demography associated factors for Smear positive PTB among patients attending Nekemte Referral Hospital, Western Ethiopia, April-May, 2012.

\begin{tabular}{|c|c|c|c|c|c|}
\hline \multirow{2}{*}{\multicolumn{2}{|c|}{ Variable }} & \multicolumn{4}{|c|}{ Sputum Smear examination result } \\
\hline & & \multirow{2}{*}{$\frac{\text { Positive }}{14}$} & \multirow{2}{*}{$\begin{array}{c}\text { Negative } \\
78\end{array}$} & \multirow{2}{*}{$\begin{array}{c}\text { COR (95\%C.I) } \\
0.897(0.394,2.045)\end{array}$} & \multirow{2}{*}{$\begin{array}{c}\text { AOR (95\% C.I) } \\
0.79(0.245,2.548)\end{array}$} \\
\hline Age & $10-38$ & & & & \\
\hline & > 38 (Mean) & 13 & 65 & 1 & 1 \\
\hline \multirow[t]{2}{*}{ Sex } & Male & 12 & 77 & $0.686(0.3,1.568)$ & $0.309(0.104,0.917)^{*}$ \\
\hline & Female & 5 & 66 & 1 & 1 \\
\hline \multirow[t]{4}{*}{ Marital Status } & Married & 19 & 86 & $1.767(0.375,8.341)$ & $0.26(0.001,0.594)^{*}$ \\
\hline & Single & 4 & 28 & $1.143(0.188,6.949)$ & $0.04(0.001,1.747)$ \\
\hline & Divorced & 2 & 13 & $1.231(0.152,9.972)$ & $1.106(0.85,14.32)$ \\
\hline & Widowed & 2 & 16 & 1 & 1 \\
\hline \multirow[t]{4}{*}{ Religion } & Protestant & 12 & 75 & $0.32(0.027,3.808)$ & $0.217(0.008,6.02)$ \\
\hline & Muslim & 3 & 21 & $0.286(0.01,4.201)$ & $0.36(0.011,12.1)$ \\
\hline & Orthodox & 11 & 45 & $0.041(0.041,5.89)$ & $0.76(0.026,22.4)$ \\
\hline & Other & 1 & 2 & 1 & 1 \\
\hline \multirow[t]{5}{*}{ Educational level } & Illiterate & 12 & 71 & $2.52(0.306,21.0)$ & $0.83(0.024,29.1)$ \\
\hline & Read \& write & 1 & 20 & $0.75(0.43,12.98)$ & $0.379(0.007,20)$ \\
\hline & Primary (1-8) & 4 & 15 & $4(0.399,40.105)$ & $17.78(1.45,217)^{\star}$ \\
\hline & $\begin{array}{l}\text { Secondary } \\
(9-12) \\
\text { Higher }\end{array}$ & 9 & 21 & $6.429(0.73,56.2)$ & $16.9(1.465,195)^{*}$ \\
\hline & $\begin{array}{l}\text { Education } \\
(>12)\end{array}$ & 1 & 15 & 1 & 1 \\
\hline \multirow{2}{*}{$\begin{array}{l}\text { Do you currently } \\
\text { have paid } \\
\text { employment? }\end{array}$} & yes & 3 & 16 & $0.992(0.268,3.67)$ & $0.32(0.024,4.17)$ \\
\hline & No & 24 & 127 & 1 & 1 \\
\hline \multirow[t]{5}{*}{ Occupation } & Farmer & 13 & 68 & $1.115(0.39,3.186)$ & $0.846(0.103,6.9)$ \\
\hline & Student & 6 & 16 & $2.187(0.61,7.843)$ & $4.411(0.15,126)$ \\
\hline & Merchant & 1 & 13 & $0.53(0.057,4.896)$ & $0.033(0.00,0.73)^{\star}$ \\
\hline & Daily labor & 1 & 11 & $0.449(0.049,4.09)$ & $0.111(0.005,2.5)$ \\
\hline & Other & 6 & 35 & 1 & 1 \\
\hline \multirow{2}{*}{$\begin{array}{l}\text { Total family } \\
\text { members }\end{array}$} & $1-5$ & 13 & 79 & $0.752(0.33,1.714)$ & $0.847(0.306,2.3)$ \\
\hline & $>5$ (Mean) & 14 & 64 & 1 & 1 \\
\hline \multirow{4}{*}{$\begin{array}{l}\text { Total monthly } \\
\text { income of the } \\
\text { family (in birr }\end{array}$} & $0-99$ & 4 & 21 & $0.635(0.156,2.58)$ & $1.086(0.098,12)$ \\
\hline & $100-499$ & 15 & 73 & $0.685(0.235,1.993)$ & $1.444(0.156,13)$ \\
\hline & $500-100$ & 2 & 29 & $0.23(0.042,1.257)$ & $0.103(0.013,0.8)^{\star}$ \\
\hline & $>1000$ & 6 & 20 & 1 & 1 \\
\hline \multirow[t]{2}{*}{ Residence area } & Urban & 7 & 39 & $0.933(0.36,2.38)$ & $0.026(0.001,0.6)^{\star}$ \\
\hline & Rural & 20 & 104 & 1 & 1 \\
\hline
\end{tabular}

*Statically significant $(P<0.05), 1=$ Reference group, COR=Crude Odd Ration, AOR=Adjust Odd Ratio, $95 \%$ C.I $=95 \%$ Confidence Interval 
Table 3: Host related associated factors for PTB among patients attending Nekemte Referral Hospital, Western Ethiopia, April-May, 2012.

\begin{tabular}{|c|c|c|c|c|}
\hline \multirow{2}{*}{ Variable } & \multicolumn{4}{|c|}{ Sputum Smear examination result } \\
\hline & Positive & Negative & COR (95\%C.I) & AOR (95\% C.I) \\
\hline \multicolumn{5}{|c|}{ Close contact history to a TB patient } \\
\hline Yes & 6 & 60 & $0.395(0.15,1.039)$ & $0.133(0.024,0.73)^{*}$ \\
\hline No & 21 & 83 & 1 & 1 \\
\hline \multicolumn{5}{|l|}{ Vaccinate for TB } \\
\hline Yes & 3 & 16 & $0.992(0.268,3.67)$ & $1.235(0.306,9.9)$ \\
\hline No & 24 & 127 & 1 & 1 \\
\hline \multicolumn{5}{|l|}{ Smoking } \\
\hline Never & 23 & 131 & $0.878(0.98,7.862)$ & $0.801(0.064,9.9)$ \\
\hline Current & 3 & 7 & $2.143(0.169,27.1)$ & $2.898(0.182,46)$ \\
\hline Ex-smoker & 1 & 5 & 1 & 1 \\
\hline \multicolumn{5}{|l|}{ Drink alcohol } \\
\hline Never & 16 & 83 & $1.446(0.301,6.94)$ & $1.704(0.317,9.1)$ \\
\hline Current & 9 & 45 & $1.5(0.291,7.731)$ & $1.137(0.195,6.6)$ \\
\hline Ex-drinking & 2 & 15 & 1 & 1 \\
\hline \multicolumn{5}{|l|}{ Drink raw milk } \\
\hline Never & 21 & 110 & $0.509(0.125,2.078)$ & $0.311(0.059,1.6)$ \\
\hline Current & 3 & 25 & $0.32(0.054,1.912)$ & $0.46(0.018,1.19)$ \\
\hline Ex-drinking raw milk & 3 & 8 & 1 & 1 \\
\hline \multicolumn{5}{|l|}{ Eat raw meat } \\
\hline Never & 8 & 52 & $0.862(0.257,2.884)$ & $1.003(0.262,3.8)$ \\
\hline Current & 14 & 63 & $1.244(0.409,3.791)$ & $2.223(0.552,8.9)$ \\
\hline Ex-eating raw meat & 5 & 28 & 1 & 1 \\
\hline \multicolumn{5}{|l|}{ Chew chat } \\
\hline Never & 24 & 130 & $0.738(0.148,3.693)$ & $0.853(0.143,5.06)$ \\
\hline Current & 1 & 5 & $0.8(0.057,11.29)$ & $0.355(0.17,7.344)$ \\
\hline Ex-chewing chat & 2 & 8 & 1 & 1 \\
\hline \multicolumn{5}{|c|}{ HIV sero-status (study participant response) } \\
\hline Positive & 8 & 38 & $0.868(0.351,2.147)$ & $0.636(0.237,1.703)$ \\
\hline Negative & 19 & 104 & 1 & 1 \\
\hline
\end{tabular}

${ }^{*}$ Statically significance $(P<0.05), 1$ =Reference group

Alvi et al., 2000, Abebe et al., 2011 and Chakraborry et al., 1995) unlike the one which is conducted in Addis Ababa, where there is no association of PTB and socio-demography (Demissie et al., 2002).

History of previous contact to PTB patients was one of hot related risk factor for PTB, which is consistent with the study conducted at Seka Health Center (Gebrie and Mimano, 2010).

A multiple variable analysis, educational level (Secondary school level), history of previous contact to PTB patients, urban residence, being male and having monthly income were identified to be a risk factors in the study area, which is similar with the study conducted in Seka Health center, Ethiopia and other countries (Gebrie and Mimano, 2010, Philip et al., 2006, TAOI, 1981, Alvi et al., 2000, and Chakraborry et al., 1995). In addition, patients with merchants were found to be associated risk factor for PTB acquiring. This similar to the study conducted in Gambia (Philip et al., 2006).

Children were not included in our study and it is very difficult to obtain sputum samples. This might have resulted in failure to identify some cases of smear-positive tuberculosis and associated risk factors, and the prevalence of smear-positive and associated risk factors pulmonary tuberculosis in children remain unknown. 
Table 4: Combined multivariable assessment of socio-demography and host related associated risk factors for PTB among patients attending Nekemte Referral Hospital, Western Ethiopia, April-May, 2012.

\begin{tabular}{|c|c|c|c|}
\hline \multirow{2}{*}{ Variable } & \multicolumn{3}{|c|}{ Sputum Smear Examination Result } \\
\hline & Positive & Negative & AOR (95\% C.I) \\
\hline \multicolumn{4}{|l|}{ Sex } \\
\hline Male & 12 & 77 & $0.89(0.016,0.506)^{*}$ \\
\hline Female & 15 & 66 & 1 \\
\hline Educational level & 12 & 71 & $0.639(0.004,96.979)$ \\
\hline Read \& write & 1 & 20 & $0.125(0.00,39.265)$ \\
\hline Primary (1-8) & 4 & 15 & $25.197(0.204,3.105)$ \\
\hline Secondary (9-12) & 9 & 21 & $538.738(4.897,592.74)^{*}$ \\
\hline Higher education (>12) & 1 & 15 & 1 \\
\hline \multicolumn{4}{|l|}{ Occupation } \\
\hline Farmer & 13 & 68 & $1(0.086,11.683)$ \\
\hline Student & 6 & 16 & $12.003(0.043,33.263)$ \\
\hline Merchant & 1 & 13 & $0.003(0.00,0.732)^{*}$ \\
\hline Daily labor & 1 & 11 & $0.144(0.004,5.826)$ \\
\hline Other & 6 & 35 & 1 \\
\hline \multicolumn{4}{|c|}{ Total monthly income of the family (in birr) } \\
\hline 0-99 & 4 & 21 & $0.055(0.001,2.613)$ \\
\hline $100-499$ & 15 & 73 & $0.52(0.01,1.817)$ \\
\hline $500-100$ & 2 & 29 & $0.002(0.00,0.131)^{*}$ \\
\hline$>1000$ & 6 & 20 & 1 \\
\hline \multicolumn{4}{|l|}{ Residence area } \\
\hline Urban & 7 & 39 & $0.26(0.001,0.691)^{*}$ \\
\hline Rural & 20 & 104 & 1 \\
\hline \multicolumn{4}{|c|}{ Close contact history to a TB patient } \\
\hline Yes & 6 & 60 & $0.133(0.024,0.737)^{*}$ \\
\hline No & 21 & 83 & 1 \\
\hline
\end{tabular}

*Statically significance $(P<0.05) 1$ =Reference group

\section{CONCLUSION}

The prevalence rate of PTB is $9.41 \%$ and $15.88 \%$ by direct and sodium hypochlorite concentration Ziehle-Nelson staining technique, respectively. The associated risk factors are level of Education [primary $(\mathrm{AOR}=17.78)$ and secondary education (AOR=736.19)], occupation (merchant, AOR $=0.03$ ), sex (male, AOR=0.089), marital status (Married, AOR $=0.26)$, monthly income $(500-100$, $A O R=0.002)$, residence area (urban, $A O R=0.39$ ) and close contact history to a TB patient $(\mathrm{OR}=\mathrm{AO} .113)$. We recommended the opportunities for intervention on the identified associated risk factors and further studies to ascertain the risk factors and magnitude at community level.

\section{ACKNOWLEDGEMENTS}

The authors acknowledge the contribution made by the Nekemte Referral Hospital Medical Director,
TB unit and Medical Laboratory workers. We are also grateful to TB suspected patients who participated in the study.

\section{REFERENCES}

Abebe, D.S., Bjune, G., Ameni, G., Biffa, D., Abebe, F. (2011). Prevalence of pulmonary tuberculosis and associated risk factors in Eastern Ethiopian Prison. The International Journal of Tuberculosis and Lung Disease 15(5):668-73.

Alvi, A.R., Hussain, S.F., Shah, M.A., Khalida, M., Shamsudin, M. (1998). Prevalence of pulmonary tuberculosis on the roof of the world. The International Journal of Tuberculosis and Lung Disease 2:909-913.

Chakraborry, A.K., Suryanarayana, H.V., Krishna Murthy, V.V., Shashidhara, A.N. (1995). Prevalence of tuberculosis in a rural area by alternative survey methods without prior radiographic screening of the population. Tubercle and Lung Disease 76: 20-24. 


\section{Eyasu Ejeta et al.,}

Demissie, M., Zenebere, B., Berhane, Y., Lindtjorn, B. (2002). A rapid survey to determine the prevalence of smear-positive tuberculosis in Addis Ababa. The International Journal of Tuberculosis and Lung Disease 6(7):580-584.

Dye, C., Williams, B. (2010). The population dynamics and control of tuberculosis. Science 328: 856-861.

Eyasu Ejeta, Mengistu Legesse, Gobena Ameni. (2012). Preliminary Study on the Epidemiology of Tuberculosis in Nekemte and Its Surroundings -Western Ethiopia. Science, Technology and Arts Research Journal 1(1): 19-26.

Federal Ministry of Health (FMOH), Ethiopia. (2007). TB, leprosy and TB/HIV prevention and control program Manual, Fourth edition. Addis Ababa, Ethiopia: [http://www.moh.gov.et].

Federal Minster of Health (FMOH), Ethiopia. (2010). Tuberculosis Prevention andControl. Addis Ababa, Ethiopia.

Federal Minster of Health (FMOH), Ethiopia. (2008). Tuberculosis, Leprosy and TB/HIV Prevention and Control Programme. Addis Ababa, Ethiopia.

Gebrie, D., Mimano, L.N. (2010). Prevalence of PTB among patients attending Seka Health Center, Jimma, Oromia, Region, Ethiopia. East African Journal of Public Health 7(3): 268-273.

Philip C. Hill, Dolly Jackson-Sillah., Simon A. Donkor, Jacob Out., Richard A. Adegbola and Christian Lienhardt. (2006). Risk factors for pulmonary
Sci. Technol. Arts Res. J., July-Sep 2013, 2(3): 85-92

tuberculosis: a clinic based case control study in the Gambia. BMC Public Health 6:156.

Styblo K. (1991). Epidemiology of tuberculosis, $2^{\text {nd }}$ edition. The Hague: Royal Netherlands Tuberculosis Association; 1991.

Sudre, P., Kochi, A. (1992). Tuberculosis: a global overview of the situation today. Bulletin of World Health Organization 70: 149-159.

Tuberculosis Association of India (TAOI) (1981). Epidemiology. In: Textbook of tuberculosis. 1st ed. New Delhi, India: Vicas Publishing House, pp 63-64.

World Health Organization (WHO). (2009). Global tuberculosis control: Epidemiology, Strategy, Financing. WHO /HTM/TB/2009.426.WHO, Geneva, Switzerland.

World Health Organization (WHO). (2010). Global tuberculosis control: Epidemiology, Strategy, Financing. WHO /HTM/TB/2010.7.WHO, Geneva, Switzerland.

World Health Organization (WHO). (2009). Global tuberculosis control: epidemiology, strategy, financing: WHO report 2009. HO, Geneva; WHO/HTM/TB/2009.411.

World Health Organization (WHO). (2010). Global tuberculosis control: epidemiology, strategy, financing: WHO report $2010 . \quad$ HO, Geneva, WHO/HTM/TB/2009.411. 